\title{
Explosive evolution of small bodies in planetary atmospheres
}

\author{
Subhon Ibadov ${ }^{1,2}$ and Firuz S. Ibodov ${ }^{1}$ \\ ${ }^{1}$ Lomonosov Moscow State University, SAI, Moscow, Russia \\ email: ibadovsu@yandex.ru \\ ${ }^{2}$ Institute of Astrophysics, TAS, Dushanbe, Tajikistan
}

\begin{abstract}
The entry of small celestial bodies such as cometary nuclei, asteroids and their large fragments, into a planetary atmosphere is accompanied by an "explosion", i.e., sudden rise in brightness and the generation of a "blast" shock wave, like the 2013 Chelyabinsk event. Fully analytic approach to the phenomenon is developed taking into account aerodynamic crushing of the body and transversal expansion of the crushed mass, that leads to impulse generation of hot plasma and a "blast" shock wave in the thin "exploding" layer.
\end{abstract}

Keywords. planets: atmospheres, comets: general, minor planets, asteroids, aerodynamic crushing, hot plasma

\section{Introduction}

Explosive evolution of small celestial bodies (cometary nuclei, asteroids, and their fragments, meteoroids) in planetary atmospheres is well known phenomenon. The physical mechanism of this phenomenon has been developed over a long time (see, e.g., Levin 1956; Grigorian et al. 2013 and references therein). Explosion of the bodies can be explained by their aerodynamic crushing at entry into the dense atmospheric layers accompanied by lateral expansion of the crushed mass. This idea was presented and justified theoretically by Grigorian (1980). The theory was further developed in connection with the 100th anniversary of the 1908 Tunguska phenomenon (Ibadov et al. 2008). Analytico-numerical theories were proposed for the collision of Comet Shoemaker-Levy 9 with Jupiter (Fortov et al. 1996 and references therein).

We develop a fully analytical approach to the explosive evolution of small bodies in planetary atmospheres, like the 15 February 2013 Chelyabinsk superbolide explosion.

\section{Explosive evolution of small bodies}

Celestial bodies enter planetary atmosphere with velocities $V_{0} \gtrsim 10-20 \mathrm{~km} / \mathrm{s}$, so that the specific kinetic energy of bodies exceeds the sublimation energy of their material, $10^{10} \mathrm{erg} / \mathrm{g}$, more than 10-100 times. Hence, sudden thermalization of the kinetic energy of bodies will be accompanied by explosive high-temperature phenomena (cf. Ibadov 1987, 1990, 1996, 2012; Ibodov \& Ibadov 2014).

The height for start of body's aerodynamic crushing in the atmosphere with density distribution as $\varrho_{a}(h)=\varrho_{0} \exp (-h / H)$, is $h_{*}=H \ln \varrho_{0} V_{0}^{2} / \sigma_{*}$. For the Chelyabinsk-like stony superbolide taking realistic values of the strength $\sigma_{*}=10^{7} \mathrm{din} / \mathrm{cm}^{2}$, entry velocity $V_{0}=20 \mathrm{~km} / \mathrm{s}, \varrho_{0}=1.3 \times 10^{-3} \mathrm{~g} / \mathrm{cm}^{3}$ and height scale $H=7 \mathrm{~km}$ we get $h_{*}=40 \mathrm{~km}$.

The height of maximum energy release, manifesting as bolide's "explosion" point, is

$$
\begin{gathered}
h_{\max }=h_{e x}=h_{*}-H \ln (1+C / b) ; \quad \Delta h_{e x}=0.7 H ; \\
V_{e x}=V_{0} / e^{1 / 2} ; \quad E_{e x}=\pi \varrho_{m} R_{0}^{3} V_{0}^{2} / 3 e ;
\end{gathered}
$$




$$
\begin{gathered}
T_{0}=A m_{p} V_{0}^{2} /\left[12 e k\left(1+z+2 x_{1} / 3\right)\right] ; \\
C=\left[3 C_{x} R_{0} \sin \alpha /(8 H)\right]^{1 / 2} ; b=3 C_{x} \varrho_{0} H\left[\exp \left(-h_{*} / H\right)\right] /\left(4 \varrho_{m} R_{0} \sin \alpha\right) .
\end{gathered}
$$

Here $\Delta h_{e x}$ is the thickness of the "exploding" layer: within this layer velocity of crushed body decreases from $0.9 V_{0}$ to $0.1 V_{0}$ and generation of a hot plasma takes place; $C_{x}$ is the drag coefficient; $\alpha$ is the angle between the body entry velocity and the local horizon, $\varrho_{m}$ and $R_{0}$ are the body density and initial radius, $A$ is the mean atomic number, $m_{p}$ is the proton mass, $k$ is the Boltzmann constant, $z$ is the mean charge multiplicity of plasma ions, $x_{1}$ is the mean relative ionization potential (cf. Ibadov et al. 2009; Ibodov \& Ibadov 2011; Grigorian et al. 2013).

The height of flare of the Chelyabinsk superbolide found from observations, $h_{e x}$ (obs.) $=$ $23 \mathrm{~km}$, indicates that the body had asteroidal nature (Marov \& Shustov 2013). Using (2.1) and (2.2), we find the theoretical value of the initial radius of the supebolide, $R_{0}$ (theor.) $=$ $20 \mathrm{~m}$, the energy of explosion, $E_{e x}=4 \times 10^{22} \mathrm{erg}$, that corresponds to $400 \mathrm{kt}$ TNT (Grigorian et al. 2013; cf. www.nasa.gov/mission_pages/asteroids/news/asteroid20130215.html).

The duration of conversion of the crushed body into plasma is $\tau_{e x}=\Delta h_{e x} / V_{e x}=$ $0.3 \mathrm{sec}$, while flight time of the superbolide was about $15 \mathrm{sec}$; the initial temperature of plasma in the exploding layer is $T_{0}=10^{4} \mathrm{~K}$, i.e., more than the temperature of the solar photosphere. Similar processes occurred at the 1908 Tunguska explosion and collision of comet SL 9 with Jupiter on July 16-22, 1994 (Fortov et al. 1996; Ibodov et al. 2010).

\section{Conclusions}

The entry of small celestial bodies of both asteroidal and cometary nature into planetary atmosphere leads to impulse generation of a high-temperature plasma as well as intense electromagnetic radiation and "blast" shock wave. These topics are relevant to the complex problem of protection of the Earth from impact hazard as well as habitability of planets.

\section{Acknowledgements}

The authors are grateful to IAU for the grant to participate to IAUS 310, to reviewers for constructive comments, to Dr. G. M. Rudnitskij for useful discussions and to E. Suyunova for technical support.

\section{References}

Fortov, V. E., Gnedin, Yu.N., Ivanov, M. F. et al. 1996, Sov. Phys. Usp., 39, 363

Grigorian, S. S. 1980, Cosmic Res., 17, 724

Grigorian, S. S., Ibodov, F. S., \& Ibadov, S. 2013, Solar Sys. Res., 47, 268

Ibadov, S. 1987, ESA, SP-278, 655

Ibadov, S. 1990, Icarus, 86, 283

Ibadov, S. 1996, Physical Processes in Comets and Related Objects, Moscow, CI

Ibadov, S. 2012, Planetary Nebulae, Proc. IAUS 283, CUP, 392

Ibadov, S., Ibodov, F. S., \& Grigorian, S. S. 2008, Int. Conf. "100 Years Tunguska Phenomenon: Past, Present, Future", Moscow, RAS

Ibadov, S., Ibodov, F. S., \& Grigorian, S. S. 2009, Universal Heliophysical Processes. Proc. IAUS 257, CUP, 341

Ibodov, F. S.,Grigorian, S. S. \& Ibadov, S. 2010 Icy Bodies of the Solar System, Proc. IAUS 263, CUP, 269

Ibodov, F. S. \& Ibadov, S. 2011, Advances in Plasma Astrophysics. Proc. IAUS 274, CUP, 92

Ibodov, F. S. \& Ibadov, S. 2014, Nature of Prominences. Proc. IAUS 300, CUP, 509

Levin, B. Yu 1956, Physical Theory of Meteors, Moscow, USSR Acad. Sci.

Marov, M. Ya \& Shustov, B. M. 2013, Geochemistry International, 51, 587 